\title{
Cirurgia periodontal de retalho de Widman modificada no sextante anterior: caso clínico
}

\author{
Rita Passos Gancho ${ }^{1 *(D)}$, Andreia Pereira ${ }^{(1 D}$, José João Mendes ${ }^{1,2}$ (D), Maria Alzira Cavacas ${ }^{1,2,3}$ (i) \\ 'Instituto Universitário Egas Moniz, Monte da Caparica, Portugal; \\ ${ }^{2}$ Centro de Investigação Interdisciplinar Egas Moniz (CiiEM), Egas Moniz, CRL, Monte de Caparica, Portugal; \\ ${ }^{3}$ Morphology Lab (CiiEM), Egas Moniz, Monte de Caparica, Portugal. \\ \mariaalziracavacas6@gmail.com
}

Recebido em: 30 setembro 2020; Revisto em: 08 outubro 2020; Aceite em: 09 outubro 2020

\section{Resumo}

Introdução: O tratamento da doença periodontal é considerado complexo, incluindo numa primeira fase uma terapia não cirúrgica, e seguidamente, uma eventual terapia cirúrgica. O retalho de Widman modificado apresenta-se como uma técnica que permite uma diminuição da profundidade de sondagem das bolsas com máxima preservação do tecido periodontal, estando indicado quando a estética é um fator importante. Descrição do caso clínico: Paciente de 53 anos, sexo feminino, diagnóstico de doença periodontal estágio IV grau B. Foi iniciado o tratamento periodontal não cirúrgico, através do alisamento radicular. Na consulta de reavaliação constatou-se que a profundidade de sondagem das bolsas não atingiu a normalidade. Prosseguiu-se o tratamento, através da técnica cirúrgica periodontal de retalho de Widman modificada no sextante anterior. Conclusões: A técnica cirúrgica de retalho de Widman modificada mostrou-se uma opção de tratamento, alcançando estabilidade e saúde periodontal.

Palavras-chave: Doença periodontal, periodontite, bolsas periodontais, cirurgia periodontal, retalho de Widman modificado.

\section{INTRODUÇÃO}

A periodontite define-se como uma doença infectoinflamatória de origem bacteriana que atinge os tecidos periodontais que dão suporte às peças dentárias (Jokstad, 2019). Esta doença provoca a destruição do ligamento periodontal e perda óssea, levando à formação de bolsas e ou recessão gengival, podendo contribuir para doenças sistémicas como diabetes e aterosclerose (Kinane et al., 2017). A periodontite apresenta a nível mundial, segundo os últimos dados da UK Adult Dental Health Survey, uma prevalência de 37\% da população adulta, sendo que $11 \%$ da população mundial sofre de periodontite severa (com bolsas superiores a $6 \mathrm{~mm}$ ) (British Society of Periodontology, 2016). Dados relativos a Portugal, mais concretamente na região sul da área metropolitana de Lisboa, um estudo com base 1.064 participantes, registou uma prevalência da periodontite de $59,9 \%$, sendo que $24 \%$ e $22,2 \%$ dos participantes apresentavam periodontite severa e moderada, respetivamente (Botelho et al., 2019).

O tratamento da periodontite é complexo, e inclui numa primeira fase um tratamento não cirúrgico e eventualmente, um tratamento cirúrgico, o qual reúne um leque diferenciado de técnicas. É consensual na literatura que o tratamento não cirúrgico deve preceder o cirúrgico, estando este indicado quando o primeiro falha (Kinane et al., 2017; Rocha et al., 2013).

$\mathrm{O}$ tratamento não cirúrgico pretende reduzir ou eliminar a placa bacteriana, reduzir a profundidade de sondagem das bolsas periodontais e controlar os fatores de risco que contribuem negativamente para o estado periodontal. Este tipo de tratamento engloba procedimentos como a raspagem e o alisamento radicular, associado por vezes a terapias adjuvantes, nomeadamente a associação de agentes antimicrobianos locais e antibióticos sistémicos, terapia a laser e a terapia fotodinâmica, propiciando a remoção do tártaro, do cemento e dentina radicular afetados (Kinane et al., 2017; Kirmani et al., 2016).

No entanto, o tratamento não cirúrgico apresenta algumas limitações, pelo que em certos casos é indicada a realização do tratamento cirúrgico como uma alternativa complementar em casos de bolsas moderadas (4-6mm) ou profundas ( $>6 \mathrm{~mm}$ ). O tratamento cirúrgico tem como objetivo a obtenção de um melhor acesso às superfícies radiculares, o estabelecimento de um contorno gengival favorável e facilitar a higienização dessas áreas (Kinane et al., 2017).

Destaca-se o retalho de Widman modificado, indicado em casos de doença periodontal estágio III e IV, com profundidade de bolsas compreendidas entre os 4 e $6 \mathrm{~mm}$, em pacientes submetidos a uma fase não cirúrgica inicial, seguida da reavaliação do tratamento periodontal. Esta técnica, inicialmente descrita por Ramfjord e Nissle, em 1974 (Wennström, Heijl \& Lindhe, 2008), e também conhecida por técnica de "raspagem a céu aberto", apresenta como vantagens a diminuição da profundidade de sondagem das bolsas com máxima preservação do tecido periodontal, a adaptação imediata pós- cirúrgica do tecido circundante, como a malha de colagénio saudável à superfície dentária, uma perda mínima óssea, pouco trauma mecânico nos tecidos periodontais e a fácil higienização do local para o paciente (Kirmani et al., 2016; Rocha et al., 2013). Contudo, comparativamente com a cirurgia de reposicionamento apical com remodelação óssea, observase maior taxa de incidência de recidiva das bolsas, levando a uma menor redução de profundidade das mesmas. Porém, garante maior preservação estética, estando indicada quando 


\section{Caso Clínico}

este é um fator relevante (Becker et al., 1987; Kirmani et al., 2016; Rocha et al., 2013). Sendo este um procedimento simples, que não recorre a osteotomia, resulta num pós-operatório simples, acompanhado de pouca mobilidade dentária (Rocha et al., 2013).

Esta técnica não está indicada em casos de presença de gengiva aderida muito estreita ou biótipo gengival fino, mais frequente na mandíbula (Rocha et al., 2013).

Este caso ilustra o tratamento da doença periodontal estágio IV grau B através de cirurgia periodontal de retalho de Widman modificada.

\section{DESCRIÇÃO DO CASO CLÍNICO}

Paciente de 53 anos, sexo feminino, apresentou-se à consulta de triagem e urgências do Instituto Universitário Egas Moniz para uma avaliação geral, com queixas de dificuldade de mastigação, referiu ainda sentir-se embaraçada com a sua aparência, com vergonha de sorrir.

A Figura 1 exibe o registo fotográfico da cavidade oral da paciente na primeira consulta. Foi diagnosticada como desdentada parcial superior (Classe II de Kennedy, Modificação 1) e inferior (Classe II de Kennedy, Modificação 2).

Foi proposto um tratamento multidisciplinar que inclui consultas no âmbito da medicina dentária preventiva, apostando na instrução e motivação para melhor higiene oral.

A nível periodontal iniciou-se o tratamento pelo diagnóstico da doença, combinando a avaliação clínica e realização do periodontograma, com recurso à análise radiográfica através do status periodontal (Fig. 2). Obteve-se o diagnóstico final de periodontite estágio IV grau B. Prosseguiu-se para o tratamento mecânico e não cirúrgico da doença periodontal, tendo sido iniciado pelo alisamento radicular de cada quadrante por consulta e a motivação para a higiene oral.

$\mathrm{Na}$ consulta de reavaliação, após cerca de 1 ano de tratamento, foi tomada a decisão clínica de prosseguir o tratamento através da cirurgia periodontal, optando-se pela técnica cirúrgica periodontal de retalho de Widman modificada no sextante anterior (Fig. 4). Este procedimento iniciou-se com uma primeira incisão paralela ao eixo do dente, uma segunda incisão intrasulcular e uma terceira incisão paralela à crista alveolar. Seguidamente procedeu-se ao descolamento do retalho e curetagem que possibilita a remoção do tecido de granulação da superfície óssea, com permanente irrigação através de soro fisiológico. Procedeu-se por fim à sinérese, através de leve pressão digital para aproximação dos bordos e sutura simples com pontos colcheiros verticais. Neste procedimento não houve necessidade de osteoplastia.
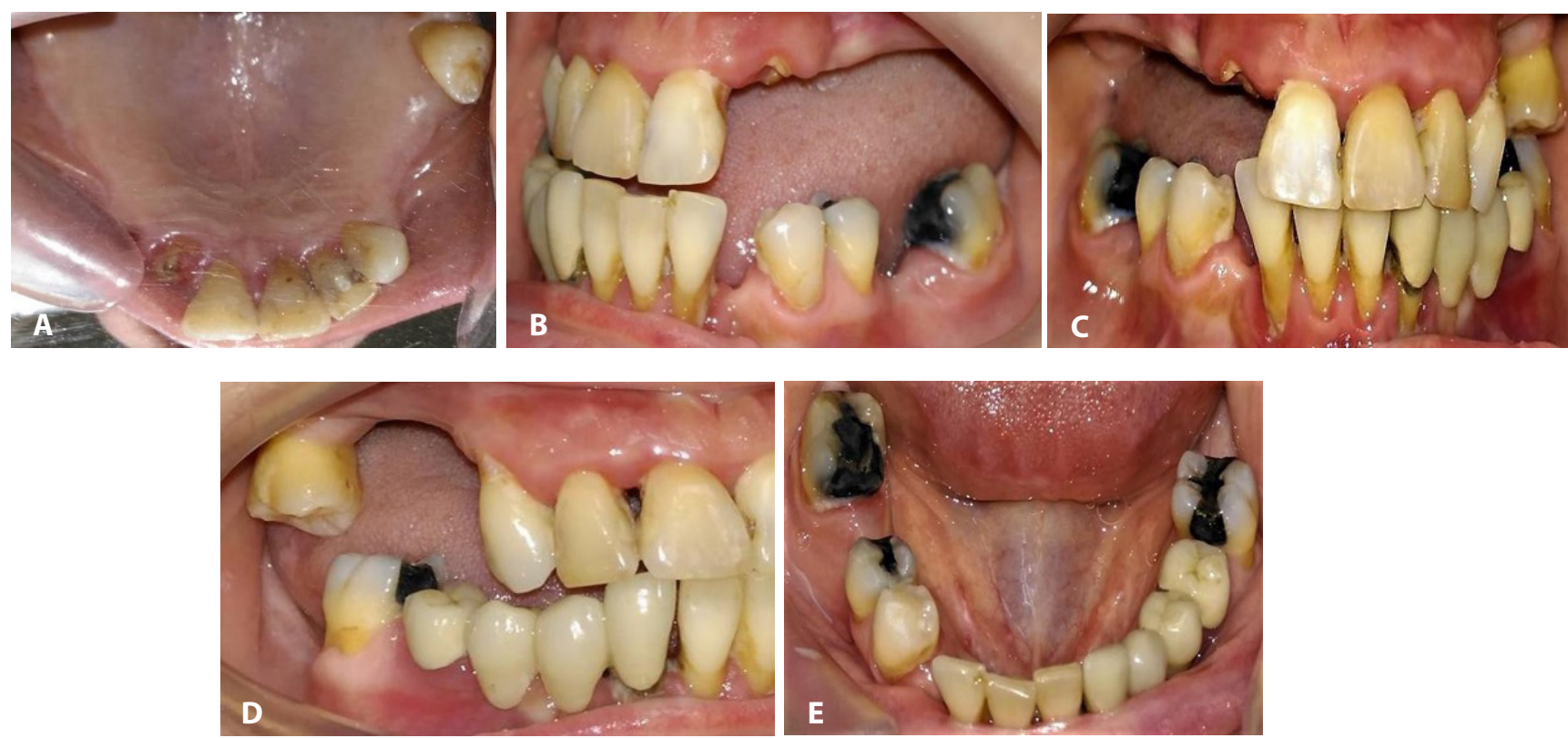

Figura 1: Registo fotográfico da cavidade oral na primeira consulta de triagem (A-E).

\section{DISCUSSÃO}

O tratamento teve início pelo tratamento mecânico e não cirúrgico da doença periodontal, mais concretamente, o alisamento radicular de cada quadrante por consulta e a motivação para a higiene oral. Esta escolha justifica-se pela sua importância como terapia isolada, podendo ser suficiente para controlar a doença periodontal. Caso o controlo da doença periodontal não ocorra apenas por meios não cirúrgicos, esta terapia inicial permite o controle da infecção e a criação um ambiente mais propício à execução da técnica cirúrgica (Kinane et al., 2017).

O tratamento através da cirurgia periodontal permitiu uma exposição adequada das superfícies radiculares, levando a um alisamento radicular mais eficiente e fácil, contribuindo para a regeneração da inserção periodontal e uma morfologia gengival que facilite o controlo de placa (Kirmani et al., 2016; López et al., 2011). O tratamento das bolsas $>4 \mathrm{~mm}$ é mais eficiente quando tratadas através de técnicas cirúrgicas (Kirmani et al., 2016).

Note-se, no entanto, o aumento da profundidade de sondagem das bolsas no dente 23 , e ainda a não regressão de nenhuma bolsa nos restantes dentes do sextante anterior (Fig. 3). Tal poderá dever-se a uma morfologia dentária que dificulta a remoção de tártaro e, portanto, a escolha de continuar com o tratamento cirúrgico ser uma opção válida. As medições 
da margem gengival foram sensivelmente semelhantes em ambas as avaliações. Constatou-se uma redução visível dos sinais clínicos de inflamação (com um índice de placa de 10\%

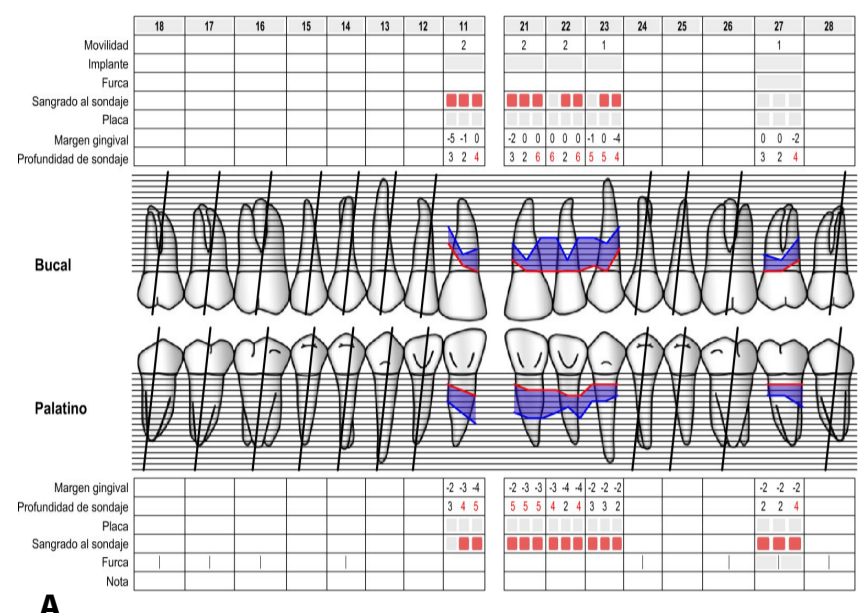

A

Figura 2: Periodontograma (A) e status radiográfico realizados na primeira consulta de triagem (B).

A técnica cirúrgica está indicada para correção de defeitos ósseos ou anatomias irregulares (Mani et al., 2018) que dificultem o tratamento não cirúrgico, sendo possivelmente esta uma das causas do insucesso no controlo das bolsas periodontais do dente 23 .

Foi escolhida a técnica cirúrgica de retalho de Widman modificada em detrimento da técnica clássica, a cirurgia óssea
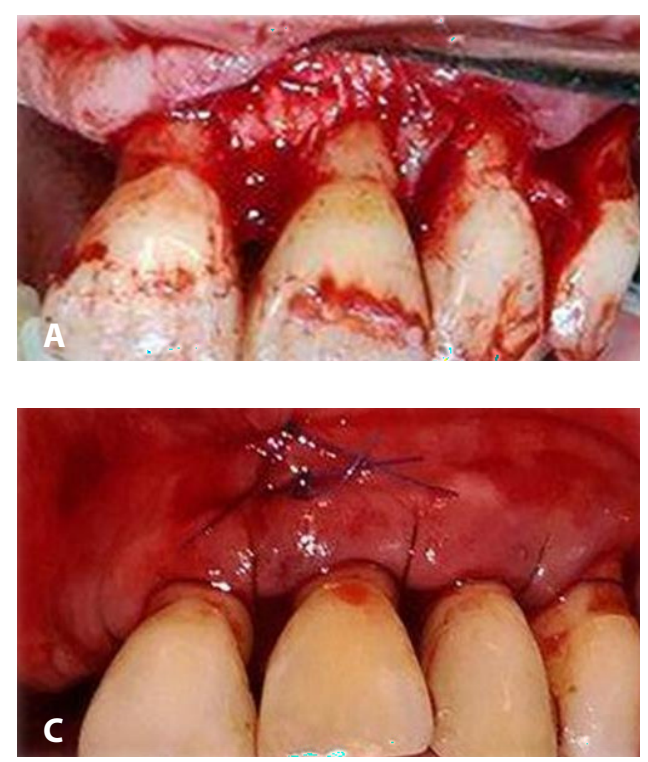

Figura 3: Cirurgia Periodontal de Widman Modificada (A-D).

com a menor perda tecidular durante e após o procedimento, resultando na formação de um epitélio juncional na superfície dos dentes promovendo a formação de novo cemento (Kinane et al., 2017; Kirmani et al., 2016; Rocha et al., 2013). Apesar de uma das limitações da técnica do retalho de Widman modificado apresentadas por Ramfjord e Nissle (1974) ser a arquitetura interproximal desfavorável após a remoção do cimento cirúrgico, este problema pode ser ultrapassado através e índice gengival de 33\%) e uma estabilização da profundidade de sondagem das bolsas de $6 \mathrm{~mm}$. Prosseguiu-se o tratamento através da técnica cirúrgica.

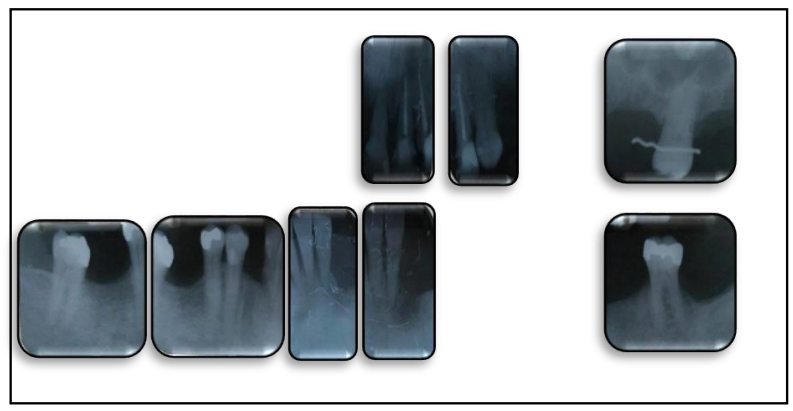

B

ressetiva. Esta última permite maior redução da profundidade de sondagem e menor taxa de recidiva das bolsas. Contudo, a longo prazo ocorre uma perda de inserção periodontal superior à técnica de Widman modificada (Cairo et al., 2015; Carnevale \& Kaldahl, 2000; López et al., 2011).

Esta técnica tem como objetivo primordial, não apenas a eliminação das bolsas periodontais, mas o seu tratamento
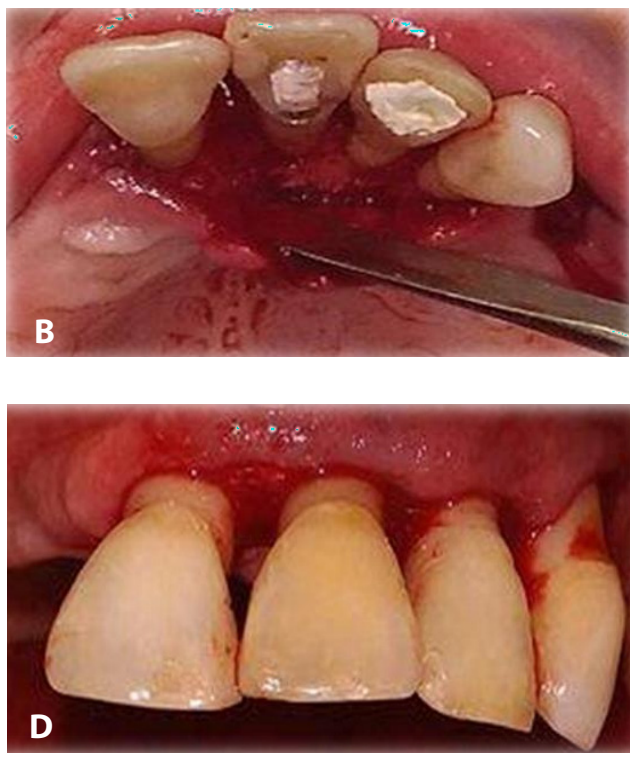

de uma higienização correta por parte do doente para permitir a recuperação desses tecidos. A técnica cirúrgica escolhida possibilita uma menor exposição radicular, maior preservação da gengiva queratinizada, cicatrização por primeira intenção e uma maior conservação estética exigida no sextante anterior em comparação com o tratamento não cirúrgico da periodontite (Mani et al., 2018). 


\section{Caso Clínico}

\section{CONCLUSÕES}

A técnica cirúrgica de retalho de Widman modificada mostrou-se uma opção válida, conseguindo alcançar-se uma condição de estabilidade e saúde periodontal, que poderá contribuir para uma reabilitação favorável.

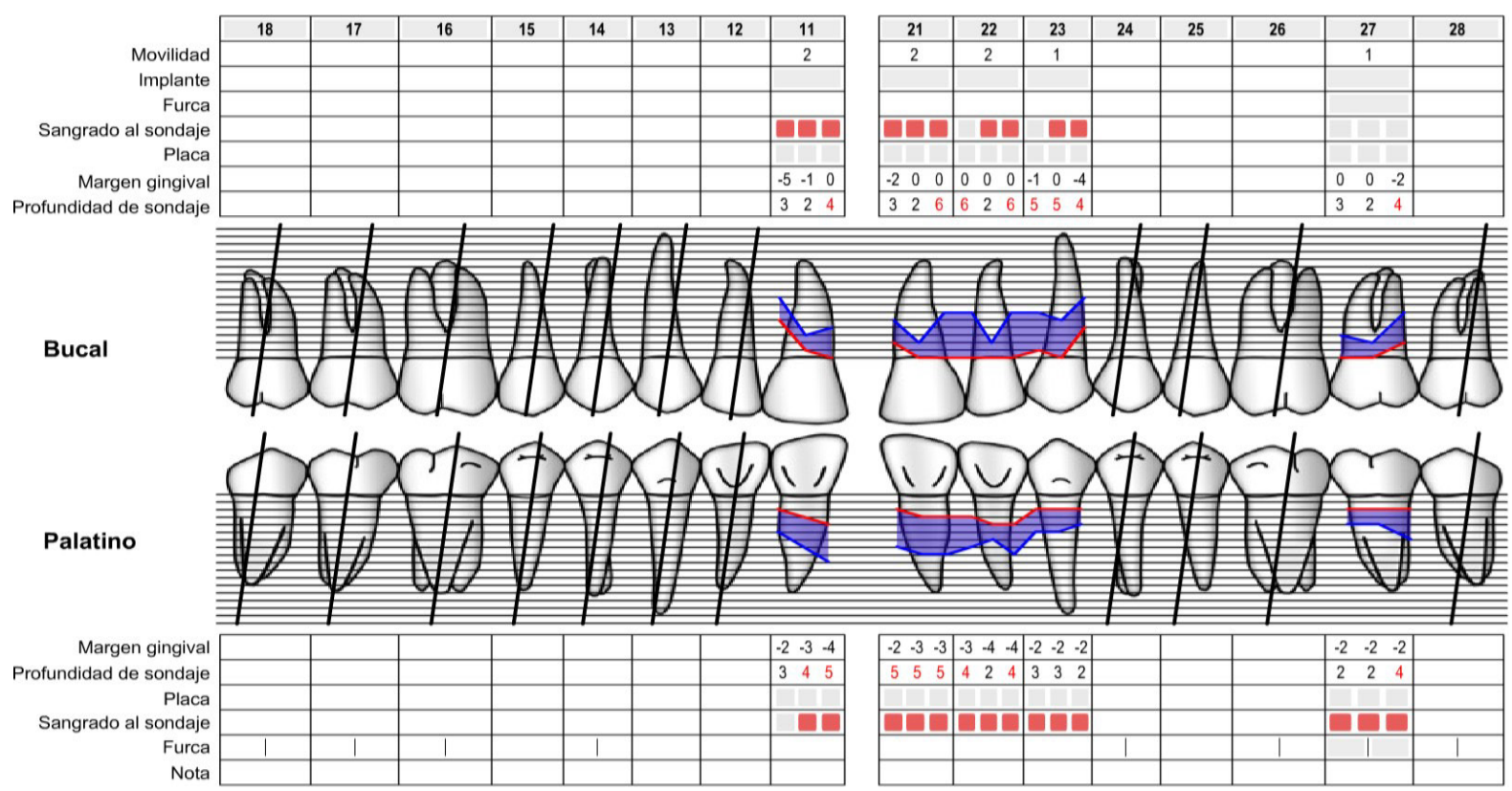

Figura 4: Periodontograma efetuado na consulta de reavaliação periodontal.

\section{REFERÊNCIAS BIBLIOGRÁFICAS}

Becker W, Becker BE, Caffesse R, Ochsenbein C, Morrison E, Prichard J. A longitudinal study comparing scaling, osseous surgery, and modified Widman procedures: results after 5 years. $J$ Periodontol 72(12):1675-1684, 2001.

Becker W, Becker BE, Prichard JF, Caffesse R, Rosenberg E, Gian-Grasso J. Root Isolation for New Attachment Procedures: A Surgical and Suturing Method:Three Case Reports. J Periodontol 58(12):819-26, 1987.

Botelho J, Machado V, Proença L, Alves R, Cavacas MA, Amaro L, Mendes JJ. Study of Periodontal Health in Almada-Seixal (SoPHiAS): a cross-sectional study in the Lisbon Metropolitan Area. Sci Rep 9(1):15538, 2019.

British Society of Periodontology. The Good Practitioner's Guide to Periodontology. BSP, Britain, 2016.

Cairo F, Carnevale G, Buti J, Nieri M, Mervelt J, Tonelli P, Pagavino G, Tonetti M. Soft- tissue re-growth following fibre retention osseous resective surgery or osseous resective surgery: a multilevel analysis. J Clin Periodontol 42(4):373-379, 201*5.

Carnevale G, KaldahI WB. Osseous resective surgery. Periodontol 2000 22:59-87, 2000.

Jokstad A. The 2018 AAP/EFP classification of periodontal diseases, a focus on "risks" as a faux ami and language gone on holiday. Clin Exp Dent Res 5(5):449-451, 2019.

Kinane D, Stathopoulou P, Papapanou P. Periodontal diseases. Nat Rev Dis Primers 3:17038, 2017.

Kirmani M, Saima S, Behal R, Jan SM, Yousuf A, Shah AF. Comparing the efficacy of scaling with root planing and modified widman flap in patients with chronic periodontitis. IAIM 3(4):168-174, 2016.

Wennström JL, Heijl L, Lindhe J, Periodontal Surgery: Access Therapy, In: Clinical Periodontology and Implant Dentistry, Lindhe J, Lang NP, Karring T (ed). Blackwell Munksgaard, 783-822: 2008.

López A, Nart J, Santos A, Alcázar J, Freixa O. Assessment of morbidity afterperiodontal resectivesurgery.JPeriodontol82 $\left(1^{*} 1^{*}\right): 1^{*} 563-1 * 569$, $201 * 1 *$.

Mani A, Maniyar SD, Kale P, S A, Thange K. Modified Widman Flap
Surgery: At a Glance. Galore International Journal of Health Sciences \& Reserach 3(4):64-69, 2018.

Ramfjord SP, Nissle RR. Modified Widman flap. J periodontol 45(8):601-7, 1974.

Rocha F, Marques T, Santos N, Sousa M. Cirurgia periodontal reparativa conservadora - retalho de Widman modificado a propósito de um caso clínico. Cadernos de saúde 6:19- 19, 2013. 